\title{
Chagas disease of the colon and rectum
}

\author{
I. P. TODD, N. H. PORTER, B. C. MORSON, BARBARA SMITH, \\ C. A. FRIEDMANN, AND R. A. NEAL
}

From St. Mark's Hospital, London

SUMmARY Chagas disease is a rare condition in patients anywhere but in Central and Latin America. This case is therefore reported because the patient was born in Britain and spent only a short time in an area where Chagas disease is endemic. It is believed that this patient is the first case of Chagas disease to be treated in Britain. Chagas disease causes a generalized degeneration of autonomic ganglia and usually presents as megaoesophagus or megacolon. The disease may also cause the heart to enlarge followed by cardiac failure.

\section{CASE REPORT}

CLINICAL HISTORY C.G., a white woman, aged 57, married, with three children, was born in Northumberland, England, but had lived in Buenos Aires, Argentine, since 1934, spending only a short period in a Chagasic area in the north of the Argentine.

Her chief complaints were of increasing dysphagia, constipation, and abdominal distension over the past six years. Defaecation only occurred with large doses of paraffin emulsion and excessive straining. She had lost $14 \mathrm{lb}$ in weight in three years. There was slight precordial pain on exertion but no other cardio-vascular symptoms.

She had had rheumatic fever in 1912, an appendicectomy in 1927, on ovarian cystectomy in 1963, and Heller's operation with total vagotomy and pyloroplasty for Chagasic megaoesophagus at the British Hospital, Buenos Aires, in June 1966.

On examination she appeared to be a generally fit woman with no evidence of anaemia: pulse 80 , regular; blood pressure $150 / 90 \mathrm{~mm} \mathrm{Hg}$.

Scars of previous operations were visible on the abdomen. Distension was marked in the loins. Faecal masses were palpable, largely on the left with tympanitic areas. The anus was lax, and the pelvic floor dropped on straining. Sigmoidoscopy to $25 \mathrm{~cm}$ showed an excessively capacious rectum and colon easily visible beyond the end of the instrument.

INVESTIGATIONS All blood tests were normal.

A chest radiograph was normal, with no signs of cardiac enlargement.

A preoperative barium meal in March 1966 showed megaoesophagus (Fig. 1) and a barium enema megacolon and megarectum involving the bowel distal to the descending colon and extending down to the anus (Figs. 2 and 3).

An intravenous pyelogram was normal.

An ECG showed mild ischaemia.

The Marchado-Guerreiro reaction was strongly positive, as was the indirect haemagglutination test.
ELECTROMYOGRAPHY Anal canal resting pressures showed a considerable reduction below normal and the capacity to increase these by voluntary contraction was diminished. Activity in the pelvic muscles at rest was normal. Response to coughing was moderate. Voluntary contraction produced only a moderate increase in potentials and this was poorly sustained, though for a full minute the increase above resting level was maintained: on ceasing voluntary contraction, pelvic muscle activity virtually disappeared. After a pause of a minute there was a slow return to weak resting activity. Straining down produced immediate and complete inhibition with a very poor closing reflex, and this action repeated completely inhibited pelvic muscle activity which persisted without any closing reflex when the patient stopped straining. Some activity returned when a voluntary contraction was made, but as soon as this ceased the muscles relapsed into inactivity.

Digital examination of the anal canal produced a slight increase in activity. There was no response to sudden tension on the sphincters and steady traction on the puborectalis sling produced complete inhibition: when traction was released there was no recovery reflex. On withdrawing the examining finger there was a weak closing reflex, followed by poor resting activity. Distension of the anal canal with a balloon after an initial burst of activity produced complete inhibition, but it was difficult to assess the reflex results as basal resting activity was exceedingly weak. The patient experienced a desire to defaecate at an intrarectal volume of $150 \mathrm{ml}$. The anal canal remained closed, demonstrating the competence of the internal sphincter. Inhibition was apparent at $100 \mathrm{ml}$. The patient defaecated the balloon easily with complete inhibition and this was followed by a moderate closing reflex. Thereafter all activity disappeared but could be temporarily reversed by voluntary contraction; subsequently the pelvic muscles relapsed into inactivity.

This examination confirmed that the sphincteric responses, particularly those concerned with continence, had been considerably weakened by straining to relieve constipation. They were, however, basically normal and if 


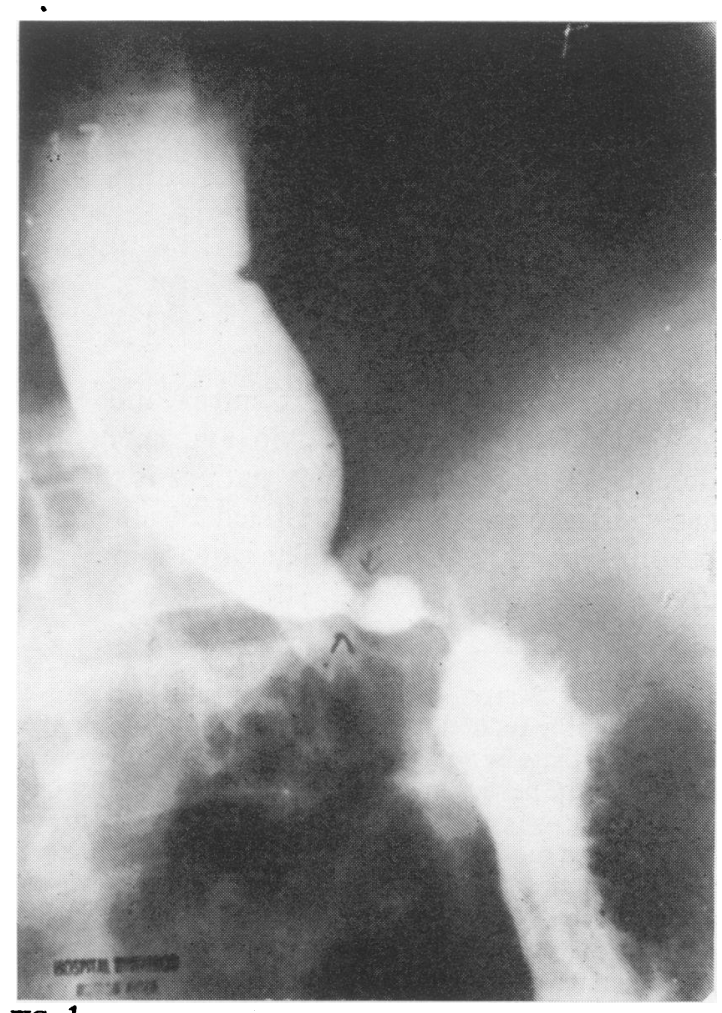

FIG. 1

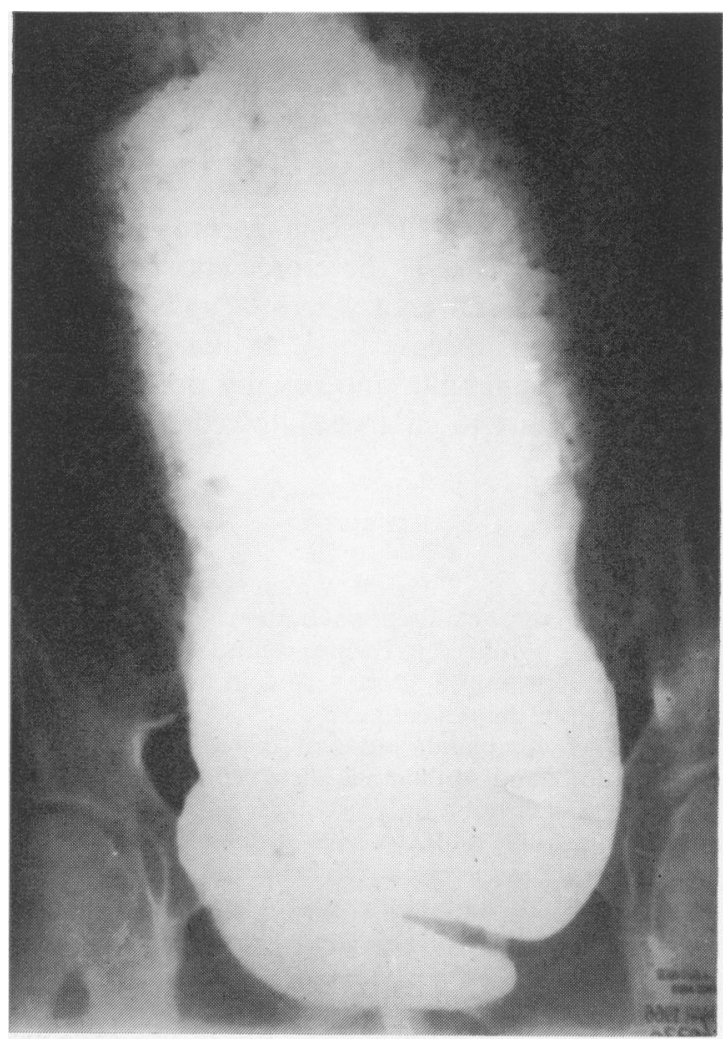

FIG. 3

FIG. 1. Barium meal showing megaoesophagus.

FIG. 2. Barium enema showing megarectum and megasigmoid.

FIG. 3. Barium enema showing megarectum but no nurrow segment. 
a normal bowel habit could be re-established a return to near normality was possible.

TREATMENT On 16 February 1967 the dilated sigmoid and upper rectum were resected. The sigmoid and rectum were found to be dilated and atonic with some muscle thickening. The remaining colon was collapsed. The small intestine was normal also. The descending colon was anastomosed to the extraperitoneal rectum.

The patient made an uninterrupted recovery from the operation, having spontaneous bowel actions. Postoperatively the anastomosis was found to be $9 \mathrm{~cm}$ from the anus.

A recent follow-up report (June 1969) suggests that the patient remains in good health with normal contour and evacuations.

PATHOLOGY The specimen consists of a piece of the lower sigmoid colon and upper rectum about $40 \mathrm{~cm}$ long (Fig. 4).

The proximal $10 \mathrm{~cm}$ of bowel has a normal calibre, but the remainder of the specimen shows a grossly increased transverse diameter of the bowel extending to the distal limit of excision where, however, it becomes a little narrower. The mucous membrane throughout the specimen appears slightly granular. There is an irregular ulcer $10 \mathrm{~cm}$ long and $0.5 \mathrm{~cm}$ wide in the central part of the specimen (Fig. 5). This has a white base but the surrounding mucosa shows little abnormality. The deep muscle layers throughout the specimen are macroscopically normal.

HISTOLOGY Sections of the ulcer show inflammation involving the submucous layer. There is infiltration with both acute and chronic inflammatory cells, including many eosinophil leucocytes. The underlying deep muscle layers appear normal apart from some congestion and a little focal inflammation, particularly in the myenteric plexus.

No Leishmania forms of Trypanosomiasis cruzi can be found.

The paraffin sections confirmed the thickening of the muscle coats, particularly the inner (Smith, 1967a and b). The myenteric plexus showed obvious loss of neurones and a very scanty inflammatory infiltrate. The cholinesterase preparations showed a normal reduction in the small number of neurones which remained. There was no increase in activity such as is seen in the agangliosis of Hirschsprung's disease. The silver impregnations, being 20 times as thick as the paraffin sections, showed a more impressive inflammatory exudate in the plexus, which was, however, very patchy. The number of ganglion cells and

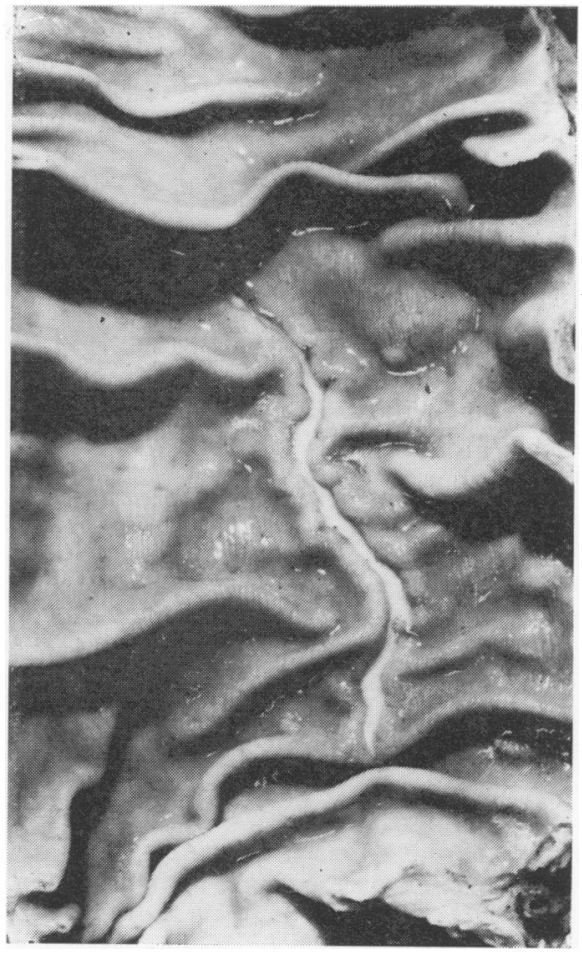

FIG. 4. Sigmoid colon and rectum.

FIG. 5. Sigmoid mucosal ulcer. 


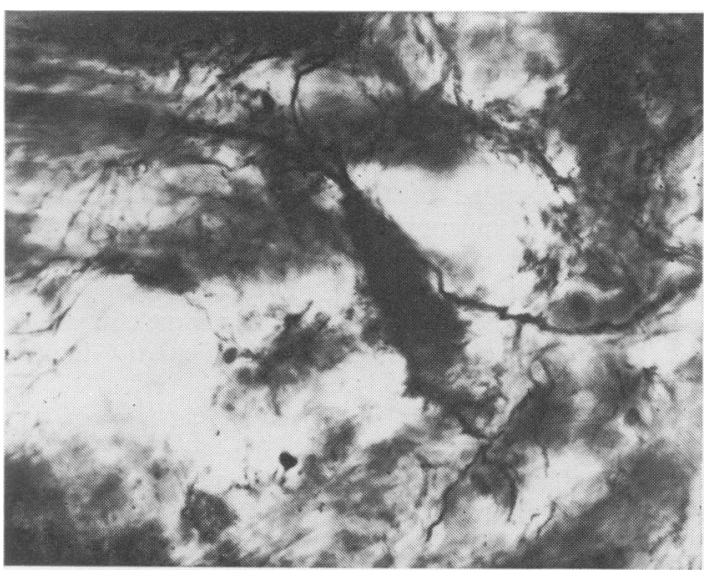

FIG. 6. Swollen neurones, ganglion cells, and axons reduced and abnormal.

axons was considerably reduced and nearly all those which remained were very abnormal. The neurones were dark and irregularly swollen and the processes were bulbous and irregular (Fig. 6). Some axons were also very swollen and a few retraction balls were seen. In addition there were single axons of regular and normal calibre which were pursuing an irregular course not running with the plexus at all (Fig. 7), and could be followed for a considerable distance weaving in and out of the muscle coats.

Koberle (1956) described a loss of myenteric neurones in Chagas disease and the pathological findings in this case are similar to those in two other cases described previously. They are compatible with the changes one would expect from destruction of the ganglion cells by the parasite. Damage to the plexus appears to result in hypertrophy of the muscle coats in man and the experimental animal. It is possibly a true work hypertrophy, as without proper peristaltic coordination, segmental contraction may be increased in an ineffective attempt to propel the contents onward. Many neurones have been lost and most of those which remain are damaged. The fine single fibres are probably regenerating axons from less severely affected neurones in another segment attempting to reinnervate the denervated muscle.

PHARMACOLOGY Full-thickness strips of longitudinal and circular muscle from both sigmoid colon and upper rectum were taken as soon as possible after operation. These were about $20 \mathrm{~mm}$ long, $2 \mathrm{~mm}$ thick, and $2 \mathrm{~mm}$ wide, and were mounted in a $10 \mathrm{ml}$ organ bath. The strips were bathed in Krebs' solution at $37^{\circ} \mathrm{C}$ and gassed with $95 \%$ oxygen $-5 \%$ carbon dioxide mixture. Recording was by isotonic lever.

Responses to acetylcholine. All strips from both sigmoid colon and rectum contracted to acetylcholine.

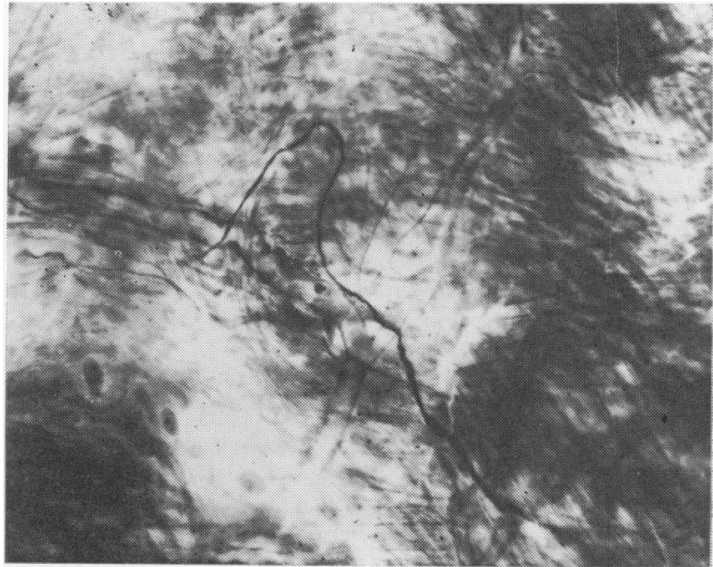

FIG. 7. Single axon.

In Fig. 8 the percentage contractions are plotted against the log-concentration of acetylcholine. Although various preparations show differences in the sensitivities of their responses, they all show similar slopes for the response curves. The variation in sensitivities was not greater than that observed in specimens taken from patients with other conditions.

Electrical responses Electrical stimulation, using 'wrap-around' electrodes, with rectangular pulses of 5 volts and 1 millisecond duration, caused increasing contractions in the range $0 \cdot 2-20$ pulses per second when applied to the circular muscle of the sigmoid colon (Fig. 9). The slope of the response curve was markedly increased after eserinization with physostigmine $(0.5 \mu \mathrm{g} / \mathrm{ml})$ for five minutes. These in turn were very greatly diminished after atropine $(0 \cdot 1 \mu \mathrm{g} / \mathrm{ml})$.

Responses to ganglion-stimulating agents Circular muscle of the sigmoid colon did not respond either to nicotine $(50 \mu \mathrm{g} / \mathrm{ml})$ or to $100 \mu \mathrm{g} / \mathrm{ml}$ dimethylphenylpiperazinium iodide (DMPP). After physostigmine a small relaxation was observed in response to DMPP. The response to acetylcholine $(0.2 \mu \mathrm{g} / \mathrm{ml})$ was however greatly enhanced after eserinization with physostigmine $(0 \cdot 2 \mu \mathrm{g} / \mathrm{ml})$.

Rectal circular muscle on the other hand gave large contractions to both nicotine and DMPP. These contractions were not preceded by relaxation as was usually observed in corresponding preparations taken from patients with other pathological conditions.

Sigmoid taenia responded to DMPP $(50 \mu \mathrm{g} / \mathrm{ml})$ with a relaxation followed by a contraction. Both phases of the response diminished rapidly after further applications. The responses to acetylcholine $(0.5 \mu \mathrm{g} / \mathrm{ml})$ were, however, not diminished by repeated application of nicotine or DMPP. Nicotine $(5-50 \mu \mathrm{g} / \mathrm{ml})$ caused relaxation followed by recovery to the original base line.

Rectal longitudinal muscle was unaffected by DMPP $(50 \mu \mathrm{g} / \mathrm{ml})$ in contradistinction to the biphasic response usually obtained from this tissue in other pathological conditions.

Noradrenaline Longitudinal muscle from both sig- 


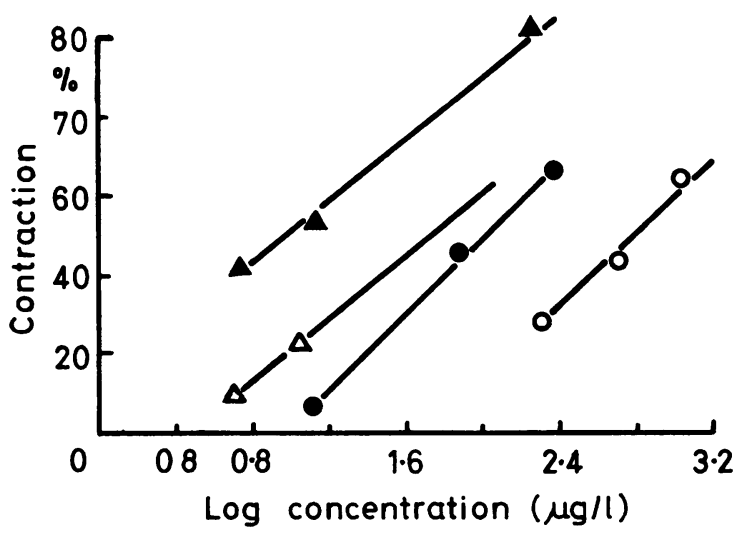

FIG. 8. Effect of acetylcholine on colonic and rectal muscle.
$\Delta$ Sigmoid taenia
$\triangle$ Rectal longitudinal muscle
- Rectal circular muscle
Sigmoid circular muscle

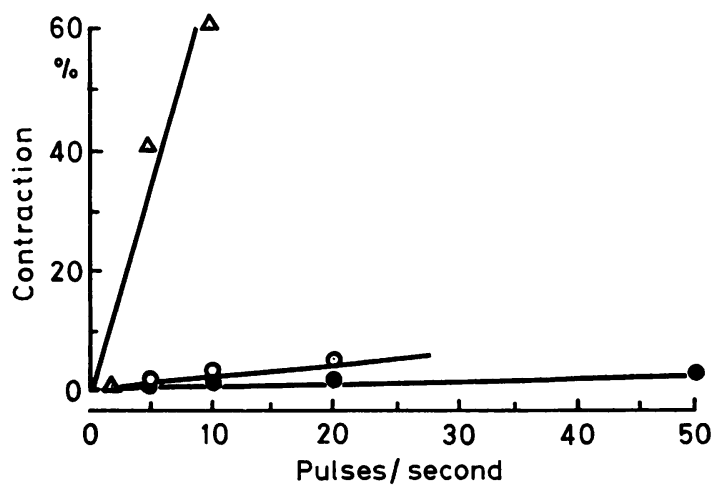

FIG. 9. Electrical responses of sigmoid circular muscle.

Alone

$\triangle$ After physostigmine $(0.5 \mu \mathrm{g} / \mathrm{ml})$

- After physostigmine $(0.5 \mu / \mathrm{ml})+$ atropine $(0.1 \mu \mathrm{g} / \mathrm{ml})$

moid and rectum responded to noradrenaline with characteristic relaxation. Circular muscle did not have sufficient tone to exhibit relaxation but pendular movements were inhibited.

The slopes of the response curves to acetylcholine suggest that the muscle coats were contracting normally to cholinergic stimuli (Niemi, Kouvalainen, and Hjelt, 1961; Pearse, 1960; and Vieira, de Godoy, and Carril, 1964).

Electrical stimulation of the circular sigmoid muscle caused contractions. The slope of the response curve was markedly increased after treatment with the anticholinesterase, physostigmine, and almost completely blocked by subsequent treatment with atropine, suggesting that the electrical pulses were stimulating a cholinergic mechanism possibly involving nerve fibres. Since, however, these contractions do not exceed about $5 \%$ of the maximum obtainable with exogenous acetylcholine, it would appear that the cholinergic nervous pathways are affected. This view was confirmed by examination of the responses to the ganglion stimulants nicotine and DMPP. The circular muscle of the sigmoid colon was unaffected by both these drugs in concentrations of up to $100 \mu \mathrm{g} / \mathrm{ml}$; since no contractions were exposed after eserinization it would appear that either parasympathetic ganglia in this tissue or postganglionic fibres from them were affected. Rectal muscle and the associated ganglion cells involved in cholinergic mechanisms appeared to be behaving more normally, since cholinergic contractions could be enhanced by eserinization. However, failure of DMPP to give rise to relaxations before contractions might perhaps suggest some damage to postganglionic adrenergic fibres in the rectal longitudinal muscle.

FURTHER THERAPY WITH COMPOUND 349C59 The patient was given one month's treatment with a new 8-aminoquinoline compound (Wellcome 349C59: 8-[6- $N^{\prime}-(3-$ hydroxybutyl) piperazinohexyl-amino]-6-methoxyquinoline di (hydrogen maleate). The dose given was $45 \mathrm{mg}$ base by mouth each day.

The results of serological tests showed that the titres dropped sharply after treatment and have remained low during seven months of follow up. However, the tests have remained positive.

No side effects attributable to the drug were observed.

TABLE

RECIPROCAL OF TITRES OF SERA BY INDIRECT HAEMAGGLUTINATION AND COMPLEMENT-FIXATION TESTS BEFORE AND AFTER TREATMENT WITH 349C59

\begin{tabular}{lcc} 
Sera & $\begin{array}{l}\text { Indirect } \\
\text { Haemagglutination } \\
\times 10^{3}\end{array}$ & $\begin{array}{l}\text { Complement } \\
\text { Fixation }\end{array}$ \\
\hline Before treatment & 256 & 1,000 \\
One month after & 64 & 250 \\
Two months after & 64 & 250 \\
Four months after & 64 & Not done \\
Seven months after & 64 & Not done
\end{tabular}

\section{DISCUSSION}

Chagas disease (Ferreira-Santos, 1961) is found in certain central areas of South and Central America extending north to the southern United States. The infecting agent is Trypanosoma cruzi, the intermediate vector being a fly or bug, commonly Triatoma sordida, the larval form of which lives in the sunbaked bricks of primitive dwellings. It is thus more 
commonly found in the backward native population of these areas. In the Leishmania form it enters and destroys the autonomic ganglia throughout the body in a quantitative manner. The effects of this destruction are most apparent in those organs and parts where the work performed is most arduous, namely, the heart and the oesophagus and distal large intestine where the contents are more solid. Sooner or later the remaining functional muscle cannot contend with the load and decompensation occurs. When this takes place in the intestine, surgery is required: a Heller's operation combined with vagotomy and pyloroplasty to cut down reflux into the decompensated, poorly contracting oesophagus is probably the best treatment for megaoesophagus though excision and replacement may be needed. In the colon and rectum removal of the dilated portion with a low anastomosis or a pullthrough procedure should be undertaken when poor bowel function and distension indicate that decompensation has occurred. It should be undertaken before the effects have progressed too far proximally and the amount of colon and rectum resected should be sufficient to give easy movement.

In this case the electromyographic results indicated that the patient had signs of the descending perineum syndrome (Parks, Porter, and Hardcastle, 1966). This was due to repeated straining at stool; otherwise the results of distending the rectum by balloon were normal, apart from rather low pressures.

Conscious rectal sensation and excitatory and inhibitory reflexes were present and apparently unimpaired by the effects of Chagas disease. For this reason a pull-through procedure was considered unwise in this case and other authors have expressed doubt as to the wisdom of this type of procedure as it may lead to incontinence (World Health Organization, 1960).

The pathologists' findings confirmed the hypertrophy of muscle, and although the function of this muscle is undoubtedly impaired, pharmacologically it behaved more or less normally in that the doseresponse curves to increasing quantities of acetylcholine were more or less parallel with each other; electrical responses of cholinergic nerves gave a very small (5\% of maximum) contraction which could be enhanced after prostigmine and almost com- pletely depressed by atropine; ganglionic responses to nicotine and DMPP were almost non-existent; rectal muscle showed possibly diminished adrenergic responses.

It is not known whether mucosal ulceration is common in this condition. It was, however, very obvious in this case and the local eosinophilic response suggested a parasitic origin.

The neuropathological changes reported by Koberle (1956) and Smith (1967b) have again been confirmed.

Treatment with 349C59 showed some effect on the parasites by an immediate drop in titre. However, the sera remained positive during a follow-up period of seven months. The significance of the residual titre is uncertain, but could be due to the continued presence of parasites or to slow disappearance of $T$. cruzi antibodies. These results encourage further chemotherapeutic studies at higher dose levels. At present it is not known whether or not the reduction of high titres by chemotherapy will be of benefit to the patient.

The epidemiology and management of Chagas disease have been described in many previous papers and no attempt is made to cover this fully here.

The work of one of us (C.A.F.) was supported by the Medical Research Council. The help of the Wellcome Research Laboratories of Tropical Medicine (R.A.N.) is acknowledged with gratitude.

\section{REFERENCES}

Ferreira-Santos, R. (1961). Megacolon and Megarectum in Chagas' Disease. Proc. roy. Soc. Med., 54, 1047.

Koberle, F. (1956). Uber das Neurotoxin des Trypanosoma Guizi. Zbl. Allg. Path. path. Anat. 95, 468-475.

Niemi, M., Kouvalainen, K., and Hjelt, L. (1961). Cholinesterases and monoamine oxidase in congenital megacolon. J. Path. Bact., 82, 363-366.

Parks, A. G., Porter, N. H., and Hardcastle, J. (1966). The syndrome of the descending perineum. Proc. roy. Soc. Med., 59, 477-482.

Pearse, A. G. E. (1960). Histochemistry: Theoretical and Applied, pp. 890-891. Churchill, London.

Smith, B. (1967a), Myenteric plexus in Hirschsprung's Disease. Gut, 8, 308-312.

(1967b). The myenteric plexus in Chagas' disease. J. Path. Bact., 94, 462-463.

Vieira, de Godoy, and Carril. (1964). Hypersensitivity of the large intestine to cholinergic agents in patients with Chagas' disease and megacolon. Rev. Bras. Gastroent., 16, 41.

World Health Organization (1960). Chagas' Disease: Report of a Study Group (Technical Report Series, (no. 202). W.H.O. Geneva. 